"This is the peer reviewed version of the following article: Angew. Chem. Int. Ed. 2014, 53, 7402-7404, which has been published in final form at https://doi.org/10.1002/anie.201403969. This article may be used for non-commercial purposes in accordance with Wiley Terms and Conditions for Self-Archiving published at http://olabout.wiley.com/WileyCDA/Section/id-820227.html." 


\title{
Preparation of $\mathrm{CO}_{2}$-diene copolymers: advancing carbon- dioxide based materials**
}

\author{
Giulia Fiorani and Arjan W. Kleij*
}

$(($ Dedication----optional $))$

\section{Keywords:}

Carbon dioxide $\cdot$ dienes $\cdot$ radical

polymerization $\cdot \mathrm{CO}_{2}$ telomerization $\cdot \mathrm{Pd}$

catalysis

Despite its physical and chemical inertness, carbon dioxide $\left(\mathrm{CO}_{2}\right)$ continues to be an attractive and alternative carbon synthon being abundant, renewable, readily available and cheap. ${ }^{[1]}$ The inertness of $\mathrm{CO}_{2}$ poses a huge challenge given the energy input required for its transformation and/or functionalization. A successful example of $\mathrm{CO}_{2}$ reutilization is represented by the development of atom-economical catalytic processes based on high-energy reactants (such as epoxides and oxetanes) leading to new functional molecules such as organic carbonates, ${ }^{[2]}$ polycarbonates and polyether-polycarbonate based polymers. ${ }^{[3]}$ Various efficient catalysts active towards $\mathrm{CO}_{2}$ /epoxide couplings have been developed in the last ten years, ${ }^{[2-4]}$ aiming at the stereo-controlled preparation of functional, cyclic carbonates ${ }^{[5]}$ as well as stereo-regular functional polymers. ${ }^{[6]}$ Further to this, some of these promising catalytic systems are currently employed in commercially feasible, industrial processes exploiting $\mathrm{CO}_{2}$ fixation using ethylene and propylene oxide as reaction partners. ${ }^{[6 c]}$ These processes furnish polyethylene carbonate, polypropylene carbonate and poly(ether)carbonate-polyols mixtures with a tailored, narrow molecular weight distribution of further (potential) use in polyurethane synthesis. ${ }^{[7]}$ The applicability of this type of polymerization reaction is still limited to polycarbonates/poly(ether)carbonates synthesis and, so far, has not been extended to another ambitious and challenging (commercial) target, the preparation of polyesters by direct copolymerization of $\mathrm{CO}_{2}$ with ethylene or dienes. This copolymerization reaction is particularly appealing since it represents a link between different renewable resources such as $\mathrm{CO}_{2}$, and cheap, widely available petroleum-derived alkenes allowing a potential evolution towards more sustainable materials. The principal obstacles preventing a successful copolymerization of these monomers include (1) a high energy barrier associated to the alternating copolymerization between ethylene/polyene and $\mathrm{CO}_{2}$ requiring excess ethylene insertion to

[*] Dr. Giulia Fiorani, Prof. Dr. Arjan W. Klei Institute of Chemical Research of Catalonia (ICIQ) Av. Països Catalans 16, 43007 Tarragona (Spain) Fax: (+34)977-920-828 E-mail: akleij@iciq.es Homepage: www.iciq.es

Prof. Dr. Arjan W. Kleij

Catalan Institute of Advanced Studies (ICREA) Pg. Lluís Companys 23, 08010 Barcelona (Spain)

[**] GF kindly acknowledges financial support from the European Community through FP7-PEOPLE-2013-IEF project RENOVACARB (grant agreement $\mathrm{N}^{\circ} 622587$ ). ICIQ, ICREA and the Spanish MINECO (CTQ2011-27385) are thanked for financial support. ensure endergonic $\mathrm{CO}_{2}$ insertion, and (2) a kinetic barrier represented by the high activation energy for $\mathrm{CO}_{2}$ insertion in the growing polymeric chain versus chain growth of the poly(ethylene) or poly(propylene). ${ }^{[8]}$

Nozaki and co-workers have now reported a reproducible and highly customizable procedure for the preparation of $\mathrm{CO}_{2}$-diene copolymers. ${ }^{[8 b, c]}$ Key to this success is the innovative use of an alternative polymerization strategy, circumventing the thermodynamic and kinetic barriers associated to direct $\mathrm{CO}_{2-}$ butadiene co-polymerization. In particular, they have employed a known meta-stable $\delta$-lactone, 3-ethylidene-6-vinyltetrahydro- $2 \mathrm{H}$ pyran-2-one (1) $]^{[9]}$ that can be easily obtained by telomerization of $\mathrm{CO}_{2}$ and butadiene in the presence of a $\mathrm{Pd} /$ phosphine ligand catalytic system (Scheme 1). Lactone $\mathbf{1}$ has been extensively studied by Behr and others in the past 30 years as a promising functional organic intermediate and versatile synthetic building block. The optimized preparation of $\mathbf{1}$ both on lab and pilot-plant scale, thereby minimizing the formation of undesired telomerization side-products, should thus be regarded as a milestone in this area. ${ }^{[10]}$

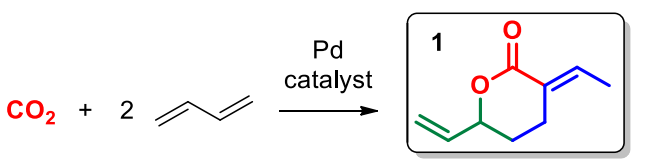

key target/intermediate

O $29 \% \mathrm{w} / \mathrm{w} \mathrm{CO}_{2}$ incorporation

○ $45 \%$ conversion

- $95 \%$ selectivity o pilot-plant scale $(30 \mathrm{~g})$

Scheme 1. Synthesis of $\delta$-lactone 1; the allylic moiety and the vinyl moiety are highlighted in blue and green, respectively.

Nozaki and co-workers have found that $\delta$-lactone 1 can easily undergo thermally initiated radical polymerization under aerobic conditions in the presence of an appropriate, thermally activated radical initiator [1,1'-azobis(cyclohexane-1-carbonitrile), V-40], observing a moderate conversion (17\%) and producing a polymer, poly-1 (Scheme 2), containing exclusively $\alpha$-subunits formed by attack of the radical chain-end on the allylic ester unit of $\mathbf{1}$ (Scheme 2). Poly-1 was characterized by a moderate $M_{\mathrm{n}}(5.7 \mathrm{kDa})$ and a narrow polydispersivity $M_{\mathrm{w}} / M_{\mathrm{n}}$ of around 1.3. The presence of Lewis acid additives such as $\mathrm{ZnCl}_{2}$ and additional solvent such as ethylene carbonate (EC) accelerated the reaction rate and improved substantially the overall yield $(48 \%)$ and $M_{\mathrm{n}}$ values $(62-85 \mathrm{kDa})$ while retaining a good $M_{\mathrm{w}} / M_{\mathrm{n}}$ distribution, but affected significantly the morphology of the resulting polymer (poly-1'); poly-1' comprises different isomeric subunits ( $\alpha, \beta$ and $\gamma$ in Scheme 2) and their presence is mediated by Lewis acid stabilization of the radical in the 
$\alpha$-position to the ester carbonyl group or hydrogen abstraction in the vinyl moiety of $\mathbf{1}$. Both poly-1 and poly-1' polymers display relatively high $\mathrm{CO}_{2}$ incorporation $(29 \% \mathrm{w} / \mathrm{w})$ and high glass transition temperatures $\left(T_{\mathrm{g}}=178-192{ }^{\circ} \mathrm{C}\right)$ making these novel polymers likely suitable as engineering plastics.

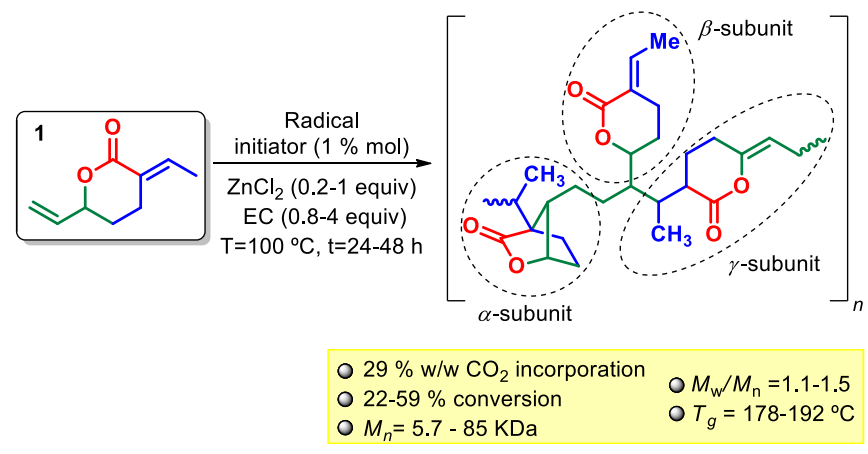

Scheme 2. Synthesis of and details for poly-1 and poly-1'.

To simplify and speed up the synthetic procedure, poly-1' was also prepared in a one-pot fashion, starting from butadiene and $\mathrm{CO}_{2}$. The scope of these one-pot polymerization reactions was extended to the incorporation of more complex diene structures (viz. 1,3pentadiene and isoprene) within the polymeric chain. The mixed telomerization of butadiene, $\mathrm{CO}_{2}$ and other $\mathrm{C}_{5}$ dienes was characterized by a lower reactivity, mainly ascribed to steric hindrance issues; however, after optimization, $\mathrm{CO}_{2}$-rich terpolymers could be obtained in good yields ( 46 and $35 \%$ yield for isoprene and 1,3-pentadiene, respectively) with relative high $\mathrm{CO}_{2}$ incorporation $(20-24 \% \mathrm{w} / \mathrm{w})$ and varying polymer properties $\left(M_{\mathrm{n}}=5.5-16 \mathrm{KDa}\right.$, $\left.M_{\mathrm{w}} / M_{\mathrm{n}}=2.0-2.5 ; T_{\mathrm{g}}=33-63^{\circ} \mathrm{C}\right)$.

By exploiting this facile aerobic radical homo-polymerization of $\delta$-lactone 1, Nozaki and co-workers have elegantly overcome the thermodynamic barrier preventing direct $\mathrm{CO}_{2}$ /butadiene copolymerization, while expanding the library of useful high-energy $\mathrm{CO}_{2}$ co-reactants. However, further characterization data (cf., mechanical and thermal stability, biodegradability) of the resulting $\mathrm{CO}_{2}$-rich polymeric materials is required to estimate their full potential and properties. Despite the slow reaction rates and the use of an excess Lewis acid co-catalyst, the possibility of obtaining $\mathrm{CO}_{2} /$ diene copolymers with a high $\mathrm{CO}_{2}$ content (between 20-29\% $\mathrm{w} / \mathrm{w}$ ) is a significant step forward towards the preparation of more sustainable plastics and could potentially lead to a bulk utilization of $\mathrm{CO}_{2}$ as a chemical feedstock. Moreover, extensive studies on the optimization of preparation procedures for intermediates of type 1 could be an excellent starting point for further process scale-up and providing new research opportunities. The combination of new, (bio)renewable based monomers with the concomitant development of one-pot polymerization strategies applicable to a discrete family of low molecular weight dienes could potentially lead to the preparation of new $\mathrm{CO}_{2}$-based copolymers with novel innovative structures, enhancing their application potential in existing and new areas of polymer science.

Received: ((will be filled in by the editorial staff))

Published online on ((will be filled in by the editorial staff))
[1] a) T. Sakakura, J.-C. Choi, H. Yasuda, Chem. Rev. 2007, 107, 23652387; b) M. Peters, B. Köhler, W. Kuckshinrichs, W. Leitner, P. Markewitz, T. E. Müller, ChemSusChem 2011, 4, 1216-1240; c) M. Cokoja, C. Bruckmeier, B. Rieger, W. A. Herrmann, F. E. Kühn, Angew. Chem. Int. Ed. 2011, 50, 8510-8537.

[2] a) M. North, R. Pasquale, C. Young, Green Chem. 2010, 12, 15141539; b) C. J. Whiteoak, N. Kielland, V. Laserna, F. Castro-Gómez, E. Martin, E. C. Escudero-Adán, C. Bo, A. W. Kleij, Chem. Eur. J. 2014, 20, 2264-2275; c) T. Ema, Y. Miyazaki, S. Koyama, Y. Yano, T. Sakai, Chem. Commun. 2012, 48, 4489-4491.

[3] a) M. R. Kember, A. Buchard, C. K. Williams, Chem. Commun. 2011, 47, 141-163; b) P. P. Pescarmona, M. Taherimehr, Cat. Sci. Technol. 2012, 2, 2169-2187; c) D. J. Darensbourg, S. J. Wilson, Green Chem. 2012, 14, 2665-2671; d) D. J. Darensbourg, Chem. Rev. 2007, 107, 2388-2410; e) G. W. Coates, D. R. Moore, Angew. Chem. Int. Ed. 2004, 43, 6618-6639; f) X.-B. Lu, W.-M. Ren, G.-P. Wu, Acc. Chem. Res. 2012, 45, 1721-1735.

[4] a) G.-P. Wu, S.-H. Wei, W.-M. Ren, X.-B. Lu, T.-Q. Xu, D. J. Darensbourg, J. Am. Chem. Soc. 2011, 133, 15191-15199; b) M. R. Kember, P. D. Knight, P. T. R. Reung, C. K. Williams, Angew. Chem. Int. Ed. 2009, 48, 931-934. c) K. Nakano, K. Nozaki, T. Hiyama, J. Am. Chem. Soc. 2003, 125, 5501-5510; d) S. I. Vagin, R. Reichardt, S. Klaus, B. Rieger, J. Am. Chem. Soc. 2010, 132, 14367-14369; e) C. T. Cohen, T. Chu, G. W. Coates, J. Am. Chem. Soc. 2005, 127, 10869-10878; f) C. J. Whiteoak, N. Kielland, V. Laserna, E. C. Escudero-Adán, E. Martin, A. W. Kleij, J. Am. Chem. Soc. 2013, 135, 1228-1231.

[5] a) W.-M. Ren, G.-P. Wu, F. Lin, J.-Y. Jiang, C. Liu, Y. Luo, X.-B. Lu, Chem. Sci. 2012, 3, 2094-2102; b) C. J. Whiteoak, E. Martin, E. Escudero-Adán, A. W. Kleij, Adv. Synth. Catal. 2013, 355, 2233-2239.

[6] a) Y. Liu, M. Wang, W.-M. Ren, K.-K. He, Y.-C. Xu, J. Liu, X.-B. Lu, Macromolecules 2014, 47, 1269-1276; b) K. Nakano, S. Hashimoto, M. Nakamura, T. Kamada, K. Nozaki, Angew. Chem. Int. Ed. 2011, 50, 4868-4871; c) Bayer and Novomer have commercialized such processes, see: $C \& E N$ 2013, $91(8), 15$.

[7] a) J. Langanke, A. Wolf, J. Hofmann, K. Bohm, M. A. Subhani, T. E. Muller, W. Leitner, C. Gurtler, Green Chem. 2014, 16, 1865-1870; b) M. R. Kember, C. K. Williams, J. Am. Chem. Soc. 2012, 134, 1567615679.

[8] a) C. J. Price, B. J. E. Reich, S. A. Miller, Macromolecules 2006, 39, 2751-2756; b) R. Nakano, S. Ito, K. Nozaki, Nature Chem. 2014, 6, 325-331; c) A. P. Dove, Nature Chem. 2014, 6, 276-277.

[9] Initial synthesis of this lactone: A. Musco, C. Perego, V. Tartiari, Inorg. Chim. Acta 1978, 28, L147-L148.

[10] a) A. Behr, K.-D. Juszak, J. Organomet. Chem. 1983, 255, 263-268; b) A. Behr, M. Heite, Chem. Ing. Tech. 2000, 72, 58-61; c) A. Behr, P. Bahke, M. Becker, Chem. Ing. Tech. 2004, 76, 1828-1832; d) A. Behr, M. Becker, Dalton Trans. 2006, 4607-4613; e) A. Behr, P. Bahke, B. Klinger, M. Becker, J. Mol. Cat. A: Chem. 2007, 267, 149-156; f) A. Behr, G. Henze, Green Chem. 2011, 13, 25-39. 
Entry for the Table of Contents:

\section{New $\mathrm{CO}_{2}$ copolymers}

Giulia Fiorani and Arjan W. Kleij*

Page - Page

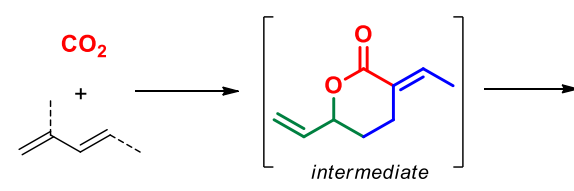

one-pot approach - new polymers with high $\mathrm{CO}_{2}$ content

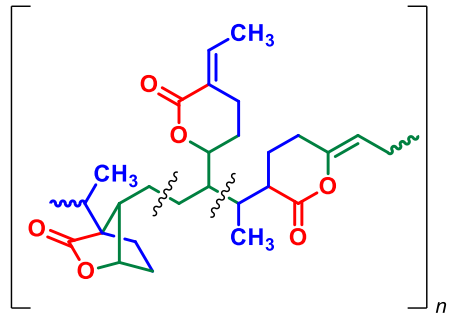

Preparation of $\mathrm{CO}_{2}$-diene copolymers: advancing carbon-dioxide based materials
Expanding the family of $\mathrm{CO}_{2}$ based materials: meta-stable $\mathrm{CO}_{2}$-diene based lactones, prepared by $\mathrm{Pd}$-catalyzed telomerization of $\mathrm{CO}_{2}$ and dienes, easily undergo aerobic radical homo-polymerization to give novel $\mathrm{CO}_{2}$-rich polymers (see Scheme). This two-step reaction set-up expands the potential applications of $\mathrm{CO}_{2}$-based copolymers adding innovative compositions, structures and properties. 